doi: 10.2306/scienceasia1513-1874.2013.39.477

\title{
Stability of turmeric constituents in natural soaps
}

\author{
Natcha Wongthongdee ${ }^{\mathrm{a}, \mathrm{b}}$, Pranee Inprakhon ${ }^{\mathrm{a}, *}$ \\ a Department of Biotechnology, Faculty of Science, Mahidol University, Rama 6 Road, Phayathai, \\ Bangkok 10400 Thailand \\ b Centre for Agricultural Biotechnology: AG-BIO/PERDO-CHE, Bangkok 10900 Thailand \\ *Corresponding author, e-mail: pranee.inp@mahidol.ac.th
}

Received 8 Jul 2012

Accepted 20 May 2013

\begin{abstract}
The suitability of using turmeric powder in natural soaps was assessed by evaluating its stability and antioxidant activity in models and actual soaps. Proper storage conditions should be considered prior to use because $63 \%$ of curcumin was lost after 3 months of storage at room temperature. Among physical properties influencing soaps, $\mathrm{pH}$ exerts the most detrimental effect on curcumin stability. Only $8 \%$ of curcumin remained 7 days after its addition into liquid soap of $\mathrm{pH}$ 9.32, whereas it was degraded completely after 21 days of the soap-bar curing process, in which pHs varied from 13 to 10. Vanillin was detected as a major by-product of degradation and might make curcumin still valuable as an antioxidant in soaps. However, the antioxidant activities of turmeric extracts treated in the model system for soaps indicated that the contribution of vanillin to antioxidant activity was not significant since its occurrence in $\mu \mathrm{g}$ was too low compared to the loss of $\mathrm{mg}$ of curcumin. In vitro assessment of the antioxidant activity of turmeric powder when extracted from a buffer of $\mathrm{pH} 10.6$ confirmed that there was no vanillin contribution in the 2,2-diphenyl-1-picrylhydrazyl (DPPH $\left.{ }^{*}\right)$ radical-scavenging activity, since the $\mathrm{IC}_{50}$ increased as a function of the decreased residual curcumin content, despite the occurrence of vanillin. In the ferric ion reducing antioxidant power (FRAP) assay, vanillin contributed slightly to the ferricreducing ability, since increasing $\mathrm{EC}_{1}$ was slowed down by gradually increased vanillin in the turmeric extract. The curcumin degradation demonstrated clearly in this study indicates that turmeric powder is not a suitable antioxidant additive and/or skin lightening agent in soap due to its physico-chemical properties.
\end{abstract}

KEYWORDS: curcumin, DPPH, FRAP, vanillin, natural cosmetics, application of plant extract

\section{INTRODUCTION}

Scientific evidence relating to health hazards from the continuous use of synthetic chemicals has initiated considerable research activity towards discovery of alternative natural products in every industrial sector. In response to this movement, cosmetic companies have created new lines of so-called 'natural cosmetics' by increasing their use of natural materials as the main components or as additives. For instance, the main ingredients of liquid- and bar-soaps, petroleum-based detergents, are replaced by alkali salts of fatty acid derived from vegetable fat and oil. Synthetic antioxidants or preservatives, such as butylated hydroxytoluene (BHT) or parabens, are replaced by various plant phenolics or essential oils ${ }^{1,2}$. In consideration of addition of synthetic colourants, the yellow colour provided by Tartrazine can be replaced by several natural colour pigments, such as curcumin, lutein, and carotenoid, which are extracted and purified from turmerics, marigold flowers, and the fruits of oil palms ${ }^{3-5}$. Recently, natural soap bars and liquids become very popular in Southeast East Asian countries due to the abundance of vegetable oils, especially coconut oil and palm oil, which are used as the main raw material using simple and cheap saponification methods. Local spices are also added to the soap formula to provide skin-care properties. Among those local spices, the powdered dry rhizome of Curcuma longa, commonly called turmeric, is one of the most widely used in natural soap bars and liquids. The dried powder of the turmeric contains $3-5 \%$ of curcumin which provides highly anti-oxidative, anti-inflammatory, and anti-carcinogenic properties ${ }^{6-8}$. Hence the use of turmeric in cosmetics and skin-care products helps to slow naturally the appearance of ageing, protect the skin against UV-radiation ${ }^{9}$ and acts as a natural healing agent for such skin conditions as eczema, acne, dry $\operatorname{skin}^{10}$, and psoriasis ${ }^{11}$.

From the formulator's point of view, the use of turmeric is very interesting for the creation of self-preserving soaps. Not only does it provide the beautiful dark orange colour for the soap, but it also protects fats and oils, the main components of natural soaps, from oxidative deterioration triggered by several factors such as oxygen concentration, light, 
and heat. Moreover, their antimicrobial activity may help to protect soaps from microbial contamination. Despite all of the benefits, questions have been raised concerning the suitability of turmeric for use in natural soaps. Basic research on the stability of curcumin in aqueous system suggests that turmeric may be not suitable for use as a natural antioxidant in soaps since it degrades rapidly at above a neutral $\mathrm{pH}$ of $9^{12}$. Based on this information, it is foreseen that the degradation of turmeric in soap products could potentially be even more serious, since the $\mathrm{pH}$ of soaps is basic according to their formulation. At present, there has been no research concerning the stability of curcumin in soap products. This systematic study provides much needed information about the application of turmeric, which may enhance its use and facilitate the development of appropriate cosmetic formulations.

The research assessed whether additive antioxidants still remained as effective as proposed after its initial incorporation into soap products. The stability in the cosmetic model system for two types of products, including bar and liquid soap, and the antioxidant capacities of turmeric powder and its degraded byproducts within the model system, were evaluated.

\section{MATERIALS AND METHODS}

\section{Materials}

Curcuminoids (94\%), vanillin (99\%), and 6-hydroxy-2,5,7,8-tetramethylchromane-2-carboxylic acid (Trolox) were purchased from Sigma-Aldrich (Germany) and used as received. A pure curcumin standard was a generous gift from Assoc. Prof. Promjit Saralamp, Department of Pharmaceutical Botany, Faculty of Pharmacy, Mahidol University, Bangkok.

\section{Collection, extraction and characterization of turmerics}

Turmerics (aged 5 months) were collected in August 2005 in Pattalung Province, Thailand. The turmeric powder was prepared according to the method of Manzan et al ${ }^{13}$ and kept in a zip-locked bag at $-20^{\circ} \mathrm{C}$ until used.

Curcuminoid extraction was performed using the modified method of Manzan et $\mathrm{al}^{13}$. The typical procedure consisted of mixing $4 \mathrm{~g}$ of turmeric powder with $50 \mathrm{ml}$ of petroleum ether in a screw-capped flask and stirring at $40^{\circ} \mathrm{C}$ for $6 \mathrm{~h}$ to remove turmeric essential oils in the supernatant. The solid obtained was then subjected to extraction using $40 \mathrm{ml}$ of absolute ethanol at $60^{\circ} \mathrm{C}$ for $1 \mathrm{~h}$. The supernatant was collected and the absolute ethanol was distilled off under a vacuum, yielding a viscous brown solid named as 'turmeric extract'. Each extraction was done in triplicate. Then, the curcuminoid content of the turmeric extracts was determined as described in ISO 5566-1982 (E). The curcuminoid content of turmeric powder was $29.7 \pm 1.4(\% \mathrm{w} / \mathrm{w})$, while the curcuminoid recovery was determined experimentally to be $98 \pm 23 \%$.

\section{Quantification of curcumin and vanillin}

The contents of curcumin in the turmeric extract were determined by high performance liquid chromatography (HPLC, Agilent 1100, Hewlett Packard, Germany) equipped with a photo-diode array detector (2487 model, Water Co., USA) and interfaced with EMPOWER PRO software. The separation was performed on a $\mathrm{C}_{18}$ Synergi Fusion RP-80A column $(5 \mu \mathrm{m}, 4.6 \times 250 \mathrm{~mm})$, with the temperature of the column oven set at $48^{\circ} \mathrm{C}$. The elution was carried out with a gradient solvent system by dual pumping. The mobile phase was composed of solvent A (acetonitrile) and solvent B (water:acetic acid, 99.75:0.25 $\mathrm{v} / \mathrm{v})$ and a flow rate of $1.0 \mathrm{ml} / \mathrm{min}$ was used. The curcumin contents were determined using the above solvents programmed linearly from 55\% solvent B in acetonitrile for $0-10 \mathrm{~min}$, then solvent $\mathrm{B}$ in acetonitrile was decreased from $55 \%$ to $40 \%$ for 10 $12 \mathrm{~min}$. The gradient then went from $40 \%$ to $55 \%$ solvent B in acetonitrile for $12-15 \mathrm{~min}$. Curcumin was detected at $425 \mathrm{~nm}$ and the retention of curcumin was about $10 \mathrm{~min}$. The curcumins were quantified using HP ChemStation software. The curcumin content, expressed as milligram of curcumin per one gram of turmeric powder $(\mathrm{mg} / \mathrm{g})$, was calculated based on the calibration curve of a curcumin standard. The experiments were done in triplicate.

The same HPLC was used to determine the vanillin content. The detection was performed at $280 \mathrm{~nm}$, with the injection volume at $30 \mu \mathrm{l}$. The elution was carried out with isocratic solvent systems with a flow rate of $1 \mathrm{ml} / \mathrm{min}$. The profile of the isocratic elution was: $12 \%$ tetrahydrofuran, $5 \%$ acetonitrile and $2 \%$ acetic acid in water, adjusted to $\mathrm{pH} 3.0$ or 4.0 with concentrated $\mathrm{KOH}$ solution ${ }^{14}$. Vanillin content, expressed as milligram of vanillin per one gram of turmeric powder $(\mathrm{mg} / \mathrm{g})$ was calculated on the basis of linear calibration of a vanillin standard. The quantification was done in triplicate.

\section{SOAP PREPARATION}

\section{Bar soap}

The oil phase, composed of coconut oil $(12.80 \mathrm{~g})$ and palm oil (54.52 g), was added into the recipient 
and stirred at $250 \mathrm{rpm}$ (IKA, Staufen, Germany) at room temperature and then, $51.2 \mathrm{ml}$ of $20 \% \mathrm{NaOH}$ solution was added. The soap mixture was stirred for approximately $30 \mathrm{~min}$ until the soap trace was formed and then $3 \%$ of turmeric powder was added. Once the turmeric powder was well mixed in, the soap base was quickly poured into moulds, covered with a plastic sheet, and left for $12 \mathrm{~h}$ at room temperature. After that, the soap was taken out of the moulds and dried in the open air for 7 days. At this time, the soap was considered ready for use. The control bar soap was made using the same procedure described above, without addition of turmeric powder.

The parameters of the soap and soap making process that might affect the curcumin stability were determined based on the BS 1715 International standard $^{15}$. These parameters are moisture content, temperature, $\mathrm{pH}$, and percentage of free caustic alkali.

\section{Liquid soap}

The steps in the liquid soap production were to make a soap gel that was subsequently dissolved in deionized water to form a liquid soap. The soap gel was prepared by mixing $100 \mathrm{~g}$ of coconut with $83 \mathrm{ml}$ of $30 \% \mathrm{KOH}$ solution. The mixture was stirred at room temperature until an opaque soap paste was obtained. The soap paste was then placed in an oven at $60^{\circ} \mathrm{C}$ for $12 \mathrm{~h}$, with air circulation, to yield a transparent soap gel. Finally, $50 \mathrm{mg}$ of soap gel was mixed with $50 \mathrm{ml}$ of deionized water and $330 \mathrm{mg}$ of turmeric powders to make the turmeric liquid soap. The moisture content, temperature, $\mathrm{pH}$, and percentage of free caustic alkali were determined using the same standard methods as for the bar soap ${ }^{15}$.

\section{STUDY OF CURCUMIN STABILITY}

\section{Under storage}

Turmeric powders of known curcumin content were kept in tightly closed dark bottles at room $\left(26-28^{\circ} \mathrm{C}\right)$ and refrigerated (about $4{ }^{\circ} \mathrm{C}$ ) temperatures. Sampling was performed each month for 6 months to determine the curcumin content by HPLC. The stabilities of curcumin under those storage conditions were evaluated by plotting the residual curcumin content against time.

\section{In model system for soaps}

The curcumin stability was assessed in a $0.01 \mathrm{M}$ phosphate buffer with the $\mathrm{pHs}$ of $9.3,10.6$, and $13.0^{16}$. For each $\mathrm{pH}$, three centrifuge tubes containing $40 \mathrm{mg}$ of turmeric powder and $10 \mathrm{ml}$ of $0.01 \mathrm{M}$ phosphate buffer were stirred at room temperature for $0,20,40$, and $60 \mathrm{~min}$. After the specific time of incubation, the tube was sampled. The $\mathrm{pH}$ of the mixture was adjusted to 2.8 with $6 \mathrm{M} \mathrm{HCl}$ solution and lyophilized for $48 \mathrm{~h}$. The lyophilized powder was extracted and the content of curcumin for each sample was measured as described earlier.

In the case of turmeric powder incubated in a $0.01 \mathrm{M}$ phosphate buffer of $\mathrm{pH} 10.6$, the content of vanillin was also quantified.

\section{In bar soap}

The back-extraction of curcumins from bar/liquid turmeric soap was performed using a surfactant precipitation technique followed by solid-phase extraction ${ }^{17}$. The essential oil of turmeric bar soap (330 mg) was extracted by $50 \mathrm{ml}$ of petroleum ether as described in 2.2. Then the solid obtained was dispersed in $40 \mathrm{ml}$ of ethanol and stirred vigorously at $60^{\circ} \mathrm{C}$ for $1 \mathrm{~h}$. The supernatant was retained. Acetonitrile $(120 \mathrm{ml})$ was then added and mixed in thoroughly to precipitate the surfactant phase. The sediment was filtered through a Whatman No. 1 filter paper, the supernatant retained and the solvent distilled off at $50{ }^{\circ} \mathrm{C}$ using a rotary evaporator. The extract obtained was dissolved with $5 \mathrm{ml}$ of absolute ethanol for HPLC analysis. The curcumin and vanillin contents were determined as described.

\section{In liquid soap}

The stability of curcumin in liquid soap was evaluated using the same procedure as described earlier for bar soap, except that only the curcumin content was determined.

\section{Assay for antioxidant capacity}

The turmeric extracts isolated from turmeric powders after incubated in phosphate buffer of $\mathrm{pH} 10.6$ at room temperature for $0,14,28,35$, and 42 days were assayed for their DPPH radical scavenging activity and ferric ion reducing antioxidant power (FRAP).

\section{DPPH ' free radical scavenging activity assay}

The $\mathrm{DPPH}^{\cdot}$ free radical scavenging activities of extracts were assayed according to the modified method of Mathew and Abreham ${ }^{18}$. The diminution of absorbance at $517 \mathrm{~nm}$, resulting from the reaction between $2.45 \mathrm{ml}$ of $0.1 \mathrm{mM}$ DPPH methanolic solution and $50 \mu \mathrm{l}$ of extracts at various concentrations $(\mathrm{mg} / \mathrm{ml}$ of the turmeric extracts in methanol) was followed for $30 \mathrm{~min}$ by a spectrophotometer (Spectronic 20 Genesgs) using methanol as a blank. The concentrations of DPPH ${ }^{*}$ (at time intervals of $0,\left[\mathrm{DPPH}^{*}\right]_{t=0}$ and $30 \mathrm{~min},\left[\mathrm{DPPH}^{*}\right]_{t=30}$ ) were determined from 
a calibration curve. The percentage of remaining $\mathrm{DPPH}^{\circ}$ in the extract, $\left(\mathrm{DPPH}^{\circ}\right)_{\mathrm{r}}$, was calculated as

$$
\left(\mathrm{DPPH}^{\cdot}\right)_{\mathrm{r}}=\left(\left[\mathrm{DPPH}^{*}\right]_{t=30}\right) /\left(\left[\mathrm{DPPH}^{*}\right]_{t=0}\right) .
$$

The obtained $\left(\mathrm{DPPH}^{\circ}\right)_{\mathrm{r}}$ was plotted against the corresponding turmeric extract concentration to obtain the amount of antioxidant necessary to decrease the initial concentration of $\mathrm{DPPH}^{*}$ to $50 \%\left(\mathrm{IC}_{50}\right)$. A lower value of $\mathrm{IC}_{50}$ indicated greater antioxidant capacity. The $\mathrm{IC}_{50}$ of the reference antioxidant, Trolox, was assayed using the same method.

\section{FRAP assay}

The ferric salt, $\mathrm{Fe}(\mathrm{III})(\mathrm{TPTZ})_{2} \mathrm{Cl}_{3}$ (TPTZ $=2,4,6$ tripyridyl-s-triazine) in FRAP reagent is used as an oxidant. The variation in FRAP of extracts was assayed using the modified method of Benzie and Strain ${ }^{19}$. The FRAP reagent was freshly prepared by mixing $2.5 \mathrm{ml}$ of a $10 \mathrm{mM}$ TPTZ solution in $40 \mathrm{mM} \mathrm{HCl}$ plus $2.5 \mathrm{ml}$ of $20 \mathrm{mM} \mathrm{FeCl} l_{3}$ and $25 \mathrm{ml}$ of $0.3 \mathrm{M}$ acetate buffer, $\mathrm{pH}$ 3.6. Briefly, $900 \mu \mathrm{l}$ of FRAP reagent warmed at $37^{\circ} \mathrm{C}$ was mixed with $90 \mu \mathrm{l}$ of distilled water and $30 \mu \mathrm{l}$ of turmeric extract. The volume was adjusted to a final value of $1020 \mu \mathrm{l}$ with distilled water. The final dilution of the test sample in the reaction mixture was $1 / 34$. Readings at the absorption maximum of $595 \mathrm{~nm}$ were taken every $15 \mathrm{~s}$ using a V-530(PC) spectrophotometer (JASCO, Inc., Maryland) equipped with a thermostatized autocell-holder. The FRAP reagent was used as blank. Temperature was maintained at $37^{\circ} \mathrm{C}$ and the reaction was monitored for up to $30 \mathrm{~min}$. The concentrations of turmeric extract (in $30 \mu \mathrm{l}$ ) were varied and plotted against absorbance values. The concentration of $\mathrm{Fe}$ (II) was determined from calibration curve of $\mathrm{FeSO}_{4}$ standard.

Aqueous solutions of known $\mathrm{Fe}(\mathrm{II})$ concentrations in the range of $300-1200 \mu \mathrm{M}\left(\mathrm{FeSO}_{4}\right)$ were used for calibration. The regression equation determined from such calibration curve was:

$$
A_{595 \mathrm{~nm}}=0.4754 x-0.194, \quad\left(R^{2}=0.9913\right),
$$

where $x$ refers to the concentration of standard $\mathrm{FeSO}_{4} \cdot 7 \mathrm{H}_{2} \mathrm{O}$ in $\mu \mathrm{M}$.

Then, the parameter 'equivalent concentration 1' or $\mathrm{EC}_{1}$, defined as the concentration of antioxidant having a ferric-TPTZ reducing ability equivalent to that of $1 \mathrm{mM} \mathrm{FeSO}_{4}$ determined from (1), was 0.6694 . The $\mathrm{EC}_{1}$ of turmeric extracts were determined by plotting their absorbance at 30 min against concentration. The concentration of the turmeric extracts having the absorbance at 30 min equal to 0.6694 was the $\mathrm{EC}_{1}$.
Table $1 \mathrm{pH}$, temperature, free caustic alkali (FCA), and moisture content of bar and liquid soaps.

\begin{tabular}{lrccc}
\hline Type of soap & \multicolumn{4}{c}{ Properties } \\
\cline { 2 - 5 } & $\mathrm{pH}$ & $\begin{array}{c}\text { Temp. } \\
\left({ }^{\circ} \mathrm{C}\right)\end{array}$ & $\begin{array}{c}\text { FCA } \\
(\%)\end{array}$ & $\begin{array}{c}\text { Moisture } \\
(\%)\end{array}$ \\
\hline Bar (at trace) & $13.00 \pm 0.01$ & 30 & 5.04 & $22.7 \pm 0.5$ \\
Bar (ready to use) & $10.64 \pm 0.00$ & 27 & 0.03 & $11.2 \pm 0.2$ \\
Liquid (ready to use) & $9.32 \pm 0.02$ & 27 & 0.00 & $53.3 \pm 4.8$ \\
\hline
\end{tabular}

The $\mathrm{EC}_{1}$ of the reference antioxidant, Trolox, was assayed using the same method.

\section{Statistical analysis}

Statistical analysis was carried out using SPSS version 11.5 (SPSS Inc. Chicago, IL, USA). The data were analysed by one-way ANOVA and by the Tukey test. A $p$-value $<0.05$ were considered to be significant. All data are presented as mean $\pm \mathrm{SD}$.

\section{RESULTS AND DISCUSSION}

\section{Properties of turmeric}

Turmeric planted in the southern part of Thailand was chosen in this study because it usually provides extracts with a higher percentage of curcumin compared to other areas. The curcuminoid content of Thai turmeric varies from $4.7-22.6 \%$, depending on age, geographical distribution, and harvest season ${ }^{20}$, but only a curcuminoid content greater than $5 \%(\mathrm{w} / \mathrm{w})$ meets Thai herbal medicinal standards. The spectrometric analysis showed a value for the curcuminoid content of turmeric in this study of $29.7 \pm 1.4 \%(\mathrm{w} / \mathrm{w})$, which is consistent with the general information and the geographical distribution mentioned above. Three curcuminoid constituents in turmeric extract were characterized by HPLC, curcumin the main component $(57.56 \pm 0.25 \%)$ followed by mono-demethoxycurcumin $(21.47 \pm 0.19 \%)$ and bis-demethoxycurcumin $(20.97 \pm 0.07 \%)$.

\section{Properties of bar and liquid soap}

The properties of bar and liquid soap that are susceptible to effect on the stability of curcumin were determined and summarized in Table 1. For bar soap, both the properties at trace (when the turmeric powder was added) and at complete saponification (ready to use) were measured.

According to these results, the model system that represented the bar and liquid soap properties should have a $\mathrm{pH}$ variance of 9.3-13, ambient temperature of $27-30{ }^{\circ} \mathrm{C}$ and moisture content of $11 \%$ to $53 \%$. The free percentage of caustic alkali was not taken into 
Table 2 Variation in curcumin contents and their percentage losses (in parentheses) during storage periods when the turmeric powders were kept in tightly closed dark bottles at room temperature $\left(26-28^{\circ} \mathrm{C}\right)$ and in a refrigerator at about $4{ }^{\circ} \mathrm{C}$.

\begin{tabular}{ccccc}
\hline \multirow{2}{*}{$\begin{array}{c}\text { Storage period } \\
\text { (months) }\end{array}$} & \multicolumn{4}{c}{ Curcumin content (mg/g) } \\
\cline { 2 - 5 } & \multicolumn{2}{c}{ Room temp. } & \multicolumn{3}{c}{ Refrigerated temp. } \\
\hline 0 & $52.5 \pm 5.1^{\mathrm{a}}$ & $(100)$ & $52.5 \pm 5.1^{\mathrm{a}}$ & $(100)$ \\
1 & $31.3 \pm 1.9^{\mathrm{b}}$ & $(59.7)$ & $39.7 \pm 1.0^{\mathrm{b}}$ & $(74.9)$ \\
2 & $26.6 \pm 0.4^{\mathrm{b}}$ & $(50.6)$ & $24.5 \pm 0.7^{\mathrm{c}}$ & $(46.5)$ \\
3 & $19.6 \pm 0.6^{\mathrm{c}}$ & $(37.3)$ & $21.1 \pm 0.3^{\mathrm{d}}$ & $(40.2)$ \\
4 & $18.9 \pm 0.1^{\mathrm{c}}$ & $(35.9)$ & $19.3 \pm 0.7^{\mathrm{d}}$ & $(36.7)$ \\
5 & $17.8 \pm 0.9^{\mathrm{c}}$ & $(33.9)$ & $18.3 \pm 0.3^{\mathrm{d}}$ & $(34.9)$ \\
6 & $17.4 \pm 2.1^{\mathrm{c}}$ & $(33.2)$ & $18.7 \pm 0.4^{\mathrm{d}}$ & $(35.6)$ \\
\hline
\end{tabular}

Data are represented as mean $\pm \mathrm{SD}(n=3)$. Means followed by different letters within a column for each test group are significantly different at $p<0.05$.

account in the model system since its influence was considered to be the same as $\mathrm{pH}$.

\section{STABILITY OF CURCUMIN}

\section{Under storage}

The efficiency of turmeric depends on the content and molecular activity of its curcuminoid constituents which can be altered by many factors such as storage, processing conditions and the physico-chemical properties of end-used products, so it is necessary to study the effect of those factors. This study focused on only the modification of curcumin contents, since it was reported to be the least stable component that degraded even in the solid form at ambient temperature, when the others were quite stable ${ }^{21}$. The content of curcumin in turmeric powder stored over 6 months at room and refrigerated temperatures was assessed (Table 2).

A significant effect of temperature was observed after 1 month of storage. It was found that the decomposition rate at room temperatures was faster than at the refrigerated temperatures. The initial content of curcumin $(52.5 \pm 5.1 \mathrm{mg} / \mathrm{g})$ decreased rapidly to $31.3 \pm 1.9 \mathrm{mg} / \mathrm{g}$ at room temperature, a percentage loss of $40 \%$, while only $25 \%$ of loss was observed at the refrigerated temperature. No significant effect of storage temperature on curcumin content was observed until 6 months, with the retention only of about $20 \mathrm{mg} / \mathrm{g}$, or an approximate loss of $60 \%$ of the curcumin. The curcumin loss during storage seems to be common to other natural colourants. To retard the loss during this study, the turmeric powders were kept at $-20{ }^{\circ} \mathrm{C}$ and the curcumin content was measured

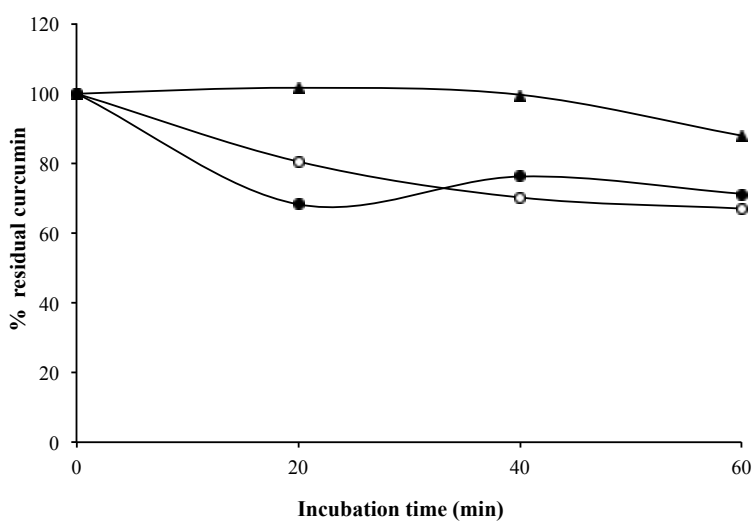

Fig. 1 Effect of $0.01 \mathrm{M}$ phosphate buffer at $\mathrm{pH} 9.3$ (open circle), pH 10 (bold triangle), and $\mathrm{pH} 13$ (filled circle) in a model system for soaps on the stability of curcumin from turmeric powder incubated at room temperatures for 20, 40, and $60 \mathrm{~min}$.

prior to performing each experiment.

\section{In model system for soaps}

The studies on curcumin stability were first carried out in the model system to avoid the complications caused by the back-extraction of low amounts of curcumin from the large amounts of fatty acid salts. After that, the stability studies were investigated in real bar and liquid soaps.

Among the properties of soap reported in Table 1, $\mathrm{pH}$ seemed to be the most influential factor on curcumin stability due to the presence of phenolic moiety in its molecule ${ }^{22}$. Hence the model system for curcumin stability studies was designed to use a $0.01 \mathrm{M}$ phosphate buffer with $\mathrm{pHs}$ of $9.3,10.6$, and 13, to simulate diverse neutral and basic conditions found in bar and liquid soaps. The curcumin contents of turmeric powder in those models were measured at 60 min intervals (Fig. 1).

The rate of curcumin loss was highest at $\mathrm{pH} 9.3$ and 13 , while curcumin tended to be most stable at $\mathrm{pH} 10.6$ as expected, and the results were consistent with earlier reports published in the literature ${ }^{22-24}$. The decomposition of curcumin is $\mathrm{pH}$-dependent and occurs faster under neutral-basic conditions. The fluorescence intensities of curcumin and curcuminoids which are related in their molecular structures, decreased as the solvent varied from neutral to highly acidic (lower than $\mathrm{pH} 1.5$ ) or basic (higher than $\mathrm{pH}$ 8.0) conditions. The intensities also decreased as the concentration of water increased ${ }^{25}$.

It is important to note the loss of curcumin at $\mathrm{pHs}$ 9.3 and 13 , which was about $33 \%$ within $1 \mathrm{~h}$. These 
Table 3 Residual curcumin content from turmeric powder in bar and liquid soaps incubated at room temperature for 1 , 3,7 , and 21 days.

\begin{tabular}{lccc}
\hline Products & $\begin{array}{c}\text { Incubation } \\
\text { time (days) }\end{array}$ & $\begin{array}{c}\text { Residual curcumin } \\
(\mathrm{mg} / \mathrm{g})\end{array}$ & $\begin{array}{c}\text { Residual } \\
\text { curcumin }(\%)\end{array}$ \\
\hline Turmeric powder & 0 & $54.0 \pm 4.5^{\mathrm{a}}$ & 100 \\
Liquid soap & 1 & $43.1 \pm 1.2^{\mathrm{b}}$ & 79.7 \\
& 3 & $23.6 \pm 1.5^{\mathrm{c}}$ & 43.7 \\
Bar soap & 7 & $4.4 \pm 1.2^{\mathrm{d}}$ & 8.1 \\
\hline
\end{tabular}

Data are presented as mean $\pm \mathrm{SD}(n=3)$. Means followed by different letters within a column for each test group are significantly different at $p<0.05$; Tukey test.

are the $\mathrm{pHs}$ at which the turmeric powders were added to liquid and bar soaps, respectively. The stability of curcumin at $\mathrm{pH} 10.6$ and the $\mathrm{pH}$ of bar soap at complete saponification might be not beneficial, since turmeric powder was added at soap trace $(\mathrm{pH} 13)$, approximately 7 days before complete saponification (pH 10.6). In the light of this, the application of turmeric powder as a spice in natural soaps might not be appropriate.

\section{In bar and liquid soaps}

The validity of the surfactant precipitation method applied for the extraction of residual curcumin from bar and liquid soaps was verified by the recovery study. A known amount of standard curcumin was spiked into the control bar/liquid soaps followed by immediate back- extraction. The recovery percentages were $95 \pm 5 \%$ and $69 \pm 12 \%$ for bar soap and liquid soap, respectively. The recovery of curcumin from bar soap showed satisfactory recoveries with 5\% error, while it was slightly lower for liquid soap. Despite this, the method was still considered acceptable for the liquid soap due to the low percentage error of about $11 \%$. When the $3 \%$ of turmeric powder was added into bar and liquid soap, the quantity of curcumin in turmeric bar soap after 21 days, and in turmeric liquid soap, after 1, 3, and 7 days of mixing, were determined (Table 3).

The residual contents of curcumin after addition to liquid soap at 1,3 , and 7 days were statistically different from the addition at 21 days in bar soap. As expected, curcumin was completely degraded in bar soaps and curcumin retention in liquid soap was only $8.1 \%$. The environment of low moisture content in the bar soap seemed not to favour the stability of curcumin. The stability studies of curcumin in both the model system for soaps and the soap products proved the unsuitability of turmeric use in soap, since
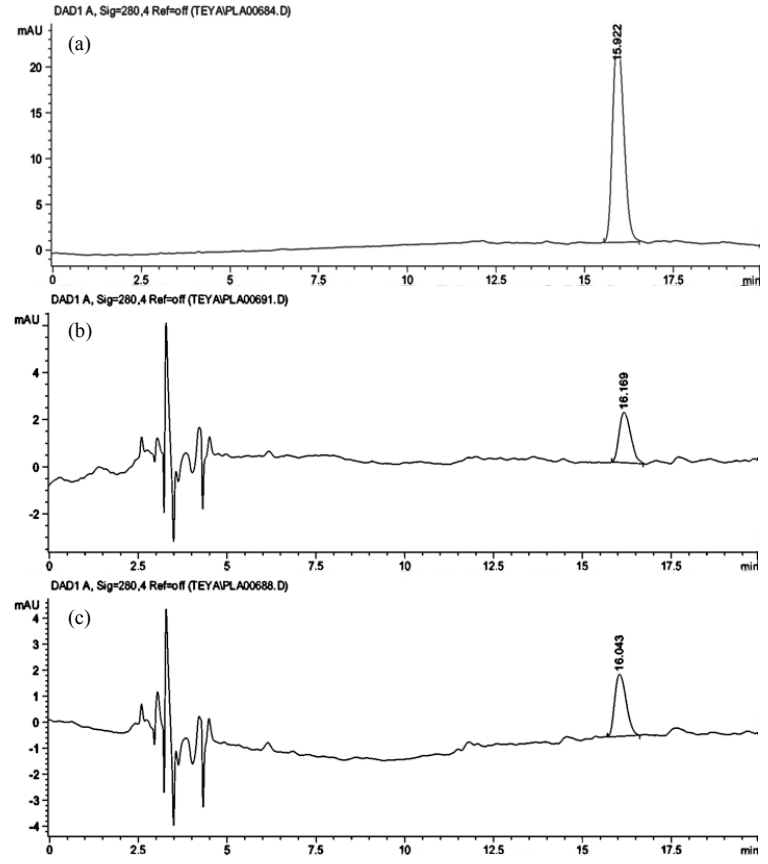

Fig. 2 HPLC chromatograms of (a) standard vanillin, (b) turmeric powder in liquid soap for 7 days, and (c) turmeric powder in liquid soap for 7 days spiked with standard vanillin.

the turmeric powder lost its curcumin, in the other words its ability to act as an antioxidant. General information concerning the stability of curcumin seems to suggest that turmeric was more appropriate to cosmetic products with a slightly acidic $\mathrm{pH}^{25,26}$.

\section{Characterization and determination of curcumin-degraded products in bar soaps}

It was reported earlier that the degradation of curcumin at $\mathrm{pHs}$ above neutral provides high-value-added products among which is vanillin ${ }^{25,27-29}$. If this is correct, the degradation of curcumin could be beneficial, since vanillin provides not only a pleasant flavournote to products, but also displays antioxidant and antimicrobial properties, as when used as a constituent in cosmetic and drug preparations ${ }^{14,28-30}$. The occurrence of vanillin was investigated in liquid soap 7 days after adding turmeric powder. The identification of vanillin was confirmed using standard vanillin spiked into the turmeric extract. The HPLC chromatograms are shown in Fig. 2.

As shown in Fig. 2, vanillin was found to be a major constituent in the extracts from soap products. Other degradation products, such as ferulic acid and vanillic acid, were not found in this study. It might be explained by the reduction of ferulic acid 


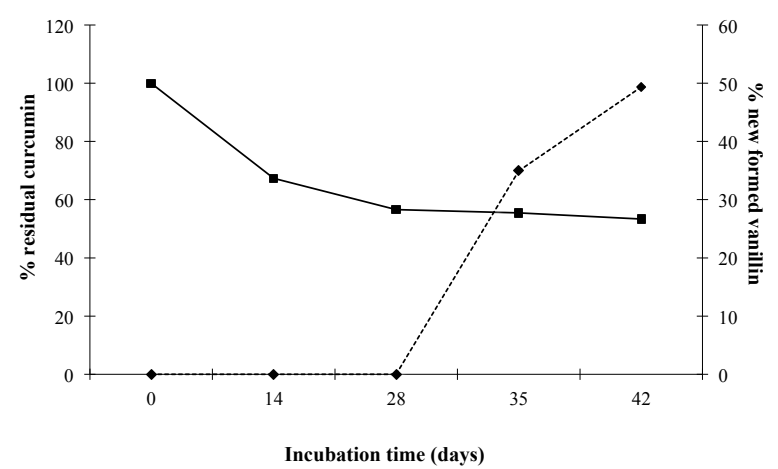

Fig. 3 Degradation curve of curcumin (squares) and formation curve of vanillin (diamonds) in a $0.01 \mathrm{M}$ phosphate buffer at $\mathrm{pH} 10.6$ during $0-42$ days.

to vanillin ${ }^{31}$ or the inability of our method to extract acidic compounds from soap at basic $\mathrm{pH}$. These data give insights into the effectiveness of turmeric for further use as an antioxidant in soap. Despite its degradation, the occurrence of vanillin as a result thereof curcumin still a valuable spice in soaps. With regard to applications, it is necessary to estimate the residual content of curcumin and its new vanillin form, and their contribution to the antioxidant capacity of the decomposed turmeric sample.

The content of natural vanillin in turmeric powder was determined as $28.2 \mu \mathrm{g} / \mathrm{g}$ prior to the incubation of such powder in a $0.01 \mathrm{M}$ phosphate buffer at $\mathrm{pH} 10.6$ for 42 days. The progress curves relating the percentage of resting curcumin and newly formed vanillin to time of incubation are shown in Fig. 3.

The initial amount of curcumin $(54.0 \mathrm{mg} / \mathrm{g}) \mathrm{de}-$ creased to $36.4,30.6,30.0$, and $28.8 \mathrm{mg} / \mathrm{g}$ (percentage losses of curcumin of $32.7 \%, 43.4 \%, 44.5 \%$, and $46.7 \%$ ) at 14, 28, 35, and 42 days, respectively. For vanillin, a rapid increase in vanillin content was detected after 28 days, from an initial content of $28.2 \mu \mathrm{g} / \mathrm{g}$ to $38.1 \mu \mathrm{g} / \mathrm{g}$ and $42.2 \mu \mathrm{g} / \mathrm{g}$ (percentage of newly formed vanillin of $34.9 \%$ and $49.4 \%$ ) after 35 days and 42 days of incubation, respectively. The finding of vanillin as a degradation product of curcumin agreed with the previous study of Wang et al ${ }^{25}$. These researchers demonstrated that when the incubation time of curcumin in a buffer solution at $37^{\circ} \mathrm{C}$ increased, vanillin would become the major degradation product. The degradation rate of curcumin appeared to relate to the formation of new vanillin. As observed at 35 days of incubation, the abrupt increase of vanillin content halted the degradation of curcumin. However, at this stage, it is difficult to explain the exact mechanism of curcumin protection by vanillin,

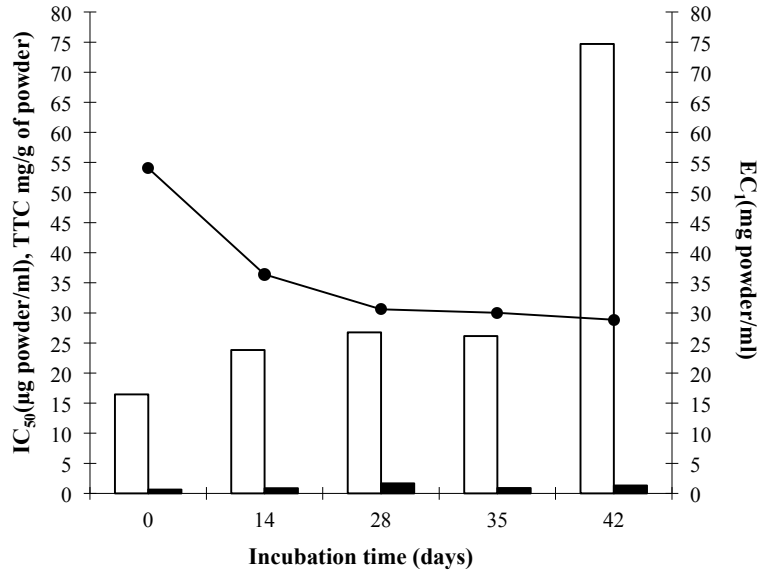

Fig. 4 Variation of the sum of curcumin and vanillin content (TTC, circles), $\mathrm{IC}_{50}$ (white bars) and $\mathrm{EC}_{1}$ (filled bars) of turmeric powder after incubation in a $0.01 \mathrm{M}$ phosphate buffer at $\mathrm{pH} 10.6$ for $0,14,28,35$, and 42 days.

because the mechanism of curcumin degradation is not known to date. It is possible that vanillin plays a role as a synergist compound of curcumin, by its capacity to reduce the curcumin radical into its parent compounds. Vanillin is a powerful scavenger of 1,1diphenyl-2-picryl hydrozyl, superoxide, and hydroxyl radicals while curcumin is a potent scavenger of the peroxy radical ${ }^{32}$. The extract of turmeric is thus a mixture of two antioxidants with different radicalscavenging activity. It would be of interest to examine the potency of the vanillin and curcumin mixture as a scavenger of free radicals.

\section{Assay for antioxidant capacity}

The evaluation of antioxidant capacity of the crude extract is a complex topic and more than one in vitro method must be used to validate results. Hence both the DPPH ${ }^{\circ}$ free radical scavenging activity and FRAP assays were used to evaluate the antioxidant activities of turmeric extracts in this study. Moreover, the validation of experimental set up was performed by determining the $\mathrm{IC}_{50}$ and $\mathrm{EC}_{1}$ of standard antioxidant, Trolox, under the same conditions. The experimental value of $\mathrm{IC}_{50}(4.7 \pm 0.5 \mu \mathrm{g} / \mathrm{ml})$ and $\mathrm{EC}_{1}$ $(0.10 \pm 0.01 \mathrm{mg} / \mathrm{ml})$ of Trolox determined in this study were consistent with the $\mathrm{IC}_{50}$ of $5.13 \mu \mathrm{g} / \mathrm{ml}$ and $\mathrm{EC}_{1}$ of $0.12 \mathrm{mg} / \mathrm{ml}$ reported in literature ${ }^{33,34}$. The methods for antioxidant activity assays in this study were thus valid. To assess $\mathrm{IC}_{50}$ and $\mathrm{EC}_{1}$ of turmeric extracts, the sum of curcumin and vanillin content (TTC) from the turmeric powders after different incubation periods were correlated with the antioxidant capacity $\mathrm{IC}_{50}$ and $\mathrm{EC}_{1}$ (Fig. 4). It should 
be recalled that a lower $\mathrm{IC}_{50}$ and $\mathrm{EC}_{1}$ indicated greater radical scavenging activity and reduction activity, respectively.

Analysis of Fig. 4 revealed an interesting decrease in TTC as a function of incubation time, despite the rapid occurrence of vanillin after 28 days of incubation. The amount of newly formed vanillin (in $\mu \mathrm{g}$ ) was too low to cause a significant change in the trend of curcumin loss (in mg). By 35 days of incubation, the decrease of TTC was accompanied by a gradual increase of $\mathrm{IC}_{50}$, indicating the reduction of free radical scavenging activity in the incubated turmeric extract. The rapid increase of $\mathrm{IC}_{50}$ after 35 days of incubation might be taken as evidence that there was no contribution of vanillin to the $\mathrm{DPPH}^{-}$free radical scavenging activity assay, since in this period the occurrence rate of vanillin was quite high. In the FRAP assay, $\mathrm{EC}_{1}$ of Trolox $(0.032 \mathrm{mg} / \mathrm{ml})$ was 20 times more active than the non treated turmeric sample $(0.635 \mathrm{mg} / \mathrm{ml})$. The detrimental effect of a buffer of $\mathrm{pH} 10.6$ on $\mathrm{EC}_{1}$ was significant, since $\mathrm{EC}_{1}$ was increased gradually to $0.870 \mathrm{mg} / \mathrm{ml}$ and $1.679 \mathrm{mg} / \mathrm{ml}$ of turmeric after 14 days and 28 days of incubation, respectively. After that, a surprising decrease of $\mathrm{EC}_{1}$, in other words an increase of reduction ability of about 2 times, was observed after prolonging incubation for another 35 days $(0.898 \mathrm{mg} / \mathrm{ml})$. This might be correlated to the content of newly formed vanillin which was high at this time (Fig. 3) and supported contributions of vanillin to enhancement of antioxidant activity in decomposed turmeric powder. The difference in $\mathrm{IC}_{50}$ and $\mathrm{EC}_{1}$ as a function of newly formed vanillin may be attributed to a difference in radical scavenging activity of vanillin from curcumin ${ }^{32}$.

In summary, our study indicates that turmeric use in natural soap as an antioxidant additive is unsuitable due to its physico-chemical properties. Although vanillin, a by-product of curcumin degradation, seemed to contribute slightly to antioxidant activity, this increase of antioxidant activity or radical scavenging activity by the newly formed vanillin was not significant compared to the decrease caused by the degradation of curcumin. If the application of turmeric in soap is needed, the proper protection of curcuminoids by encapsulation should be considered.

Acknowledgements: This study is partially supported by the Centre of Excellence for Agricultural Biotechnology, Science and Technology Postgraduate Education and Research Development Office (PERDO), Commission on Higher Education, Ministry of Education.

\section{REFERENCES}

1. Thongdon-A J, Inprakhon P (2009) Composition and biological activities of essential oils from Limnophila geoffrayi Bonati. World J Microbiol Biotechnol 25, 1313-20.

2. Cowan MM (1999) Plant product as antimicrobial agents. Clin Microbiol Rev 12, 564-82.

3. Sowbhagya HB, Smitha S, Sampathu SR, Krishnamurthy N, Bhattacharya S (2005) Stability of watersoluble turmeric colorant in an extruded food product during storage. J Food Eng 67, 367-71.

4. Hadden LW, Watkins HR, Levy WL, Regaado E, Rivadeneira MD, Breeman BR, Schwartz JS (1999) Carotenoid composition of marigold (Tagetes erecta) flower extract used as nutritional supplement. $J \mathrm{Agr}$ Food Chem 47, 4189-94.

5. Mortensen A (2006) Carotenoids and other pigments as natural colorants. Pure Appl Chem 78, 1477-91.

6. Cronin JR (2003) Curcumin: old spice is a new medicine. Focus Alternative Compl Ther 9, 34-8.

7. Araújo CAC, Leon LL (2001) Biological activities of Curcuma longa L. Mem Inst Oswaldo Cruz 96, 723-8.

8. Deng SL, Chen WF, Zhou B, Yang L, Liu ZL (2006) Protective effects of curcumin and its analogues against free radical-induced oxidative haemyolysis of human red blood cells. Food Chem 98, 112-9.

9. Korać RR, Khambholja KM (2011) Potential of herbs in skin protection from ultraviolet radiation. Phcog Rev 5, 164-73.

10. Zanwar AA (2013) Bioactive dietary factors and plant extracts in dermatology nutrition and health. In: Watson RR, Zivadi S (eds) Curcuma longa: Use for Skin Disease Care. Human press, New York, pp 391-6.

11. Sun J, Han J, Zhao Y, Zhu Q, Hu J (2012) Curcumin induces apoptosis in tumor necrosis factor-alpha-treated HaCaT cells. Int Immunopharm 13, 170-4.

12. Tønnesen HH, Karlsen J (1985) Studies of curcumin and curcuminoids. VI. Kinetics of curcumin degradation in aqueous solution. Z Lebensm Unters Forsch $\mathbf{1 8 0}$, 402-4.

13. Manzan ACCM, Toniolo FS, Bredow E, Povh NP (2003) Extraction of essential oil and pigments from Curcuma longa [L.] by steam distillation and extraction with volatile solvents. J Agr Food Chem 51, 6802-7.

14. Tønnesen HH, Karlsen J (1987) Studies on curcumin and curcuminoids. X. The use of curcumin as a formulation aid to protect light-sensitive drugs in soft gelatin capsules. Int J Pharm 38, 247-9.

15. British Standards Institution (BS 1175) (1989) Analysis of soaps. In: Part 2 Quantitative Test Method. BSI, London.

16. Williams CA, Chase MW (1967) Methods in Immunology and Immunochemistry: Vol. 2, Physical and Chemical Methods. Academic Press, New York.

17. Giokas DL, Sakkas VA, Albanis TA, Lampropoulou DA (2005) Determination of UV-filter residues in 
bathing water by liquid chromatography UV-diode array and gas chromatography-mass spectrometry after micelle mediated extraction-solvent back extraction. J Chrom A 1077, 19-27.

18. Mathew S, Abraham TE (2006) In vitro antioxidant activities and scavenging effects of Cinnamomum verum leaf extract assayed by different methodologies. Food Chem Toxicol 44, 198-206.

19. Benzie IFF, Strain JJ (1996) The ferric reducing ability of plasma (FRAP) as a measure of "antioxidant power": the FRAP assay. Anal Biochem 239, 70-6.

20. Chavalittunrong P, Dechatiwongse T (1998) Quality evaluation of turmeric. Thai J Pharm Sci 13, 317-27.

21. Pfeiffer E, Höhle S, Solyom AM, Metzler M (2003) Studies on the stability of turmeric constituents. J Food Eng 56, 257-9.

22. Lin JK, Lin-Shiau SY (2001) Mechanisms of cancer chemoprevention by curcumin. Proc Natl Sci Counc Republic China B 25, 59-66.

23. Tønnesen HH, Arrieta AF, Lerner D (1995) Studies on curcumin and curcuminoids. XXIV. Characterization of the spectroscopic properties of the naturally occurring curcuminoids and selected derivatives. Pharmazie 50, 689.

24. Bong PH (2000) Spectral and phytophysical behaviors of curcumin and curcuminoids. Bull Kor Chem Soc 21 , 81-6.

25. Wang YJ, Pan M, Cheng AL, Lin LI (1997) Stability of curcumin in buffer solutions and characterization of its degradation products. J Pharmaceut Biomed Anal 15, 867-1876.

26. Oetari S, Sudibyo M, Commandeur JNM, Samhoedi R, Vermeulen NPE (1996) Effects of curcumin on cytochrome P450 and glutathione S-transferase activities in rat liver. Biochem Pharmacol 51, 39-45.

27. Burri J, Graf M, Lambelet P, Löliger J (1989) Vanillin: more than a flavouring agent-a potent antioxidant. J Sci Food Agr 48, 49-56.

28. Anklam E, Gaglione S, Müller A (1997) Oxidation behaviour of vanillin in dairy products. Food Chem $\mathbf{6 0}$, 43-51.

29. Fitzgerald DJ, Stratford M, Gasson MJ, Ueckert J, Bos A, Narbad A (2004) Mode of antimicrobial action of vanillin against Escherichia coli, Lactobacillus plantarum and Listeria innocua. J Appl Microbiol 97, 104-13.

30. Karathanos VT, Mourtzinos I, Yannakopoulou K, Andrikopoulos NK (2006) Study of the solubility, antioxidant activity and structure of inclusion complex of vanillin with $\beta$-cyclodextrin. Food Chem 101, 652-8.

31. Zenk MH (1965) Biosynthese von vanillin in Vanilla planifolia Andr. Z Pflanzenphysiol 53, 404-14.

32. Liu J, Mori A (1993) Antioxidant and pro-oxidant activities of $p$-hydroxybenzyl alcohol and vanillin: effects on free radicals, brain peroxidation and degradation of benzoate, deoxyribose, amino acids and DNA. $\mathrm{Neu}$ ropharmacology 32, 659-69.
33. Mazor D, Greenberg L, Shamir D, Meyerstein D, Meyerstein N (2006) Antioxidant properties of bucillamine: Possible mode of action. Biochem Biophys Res Comm 349, 1171-5.

34. Pulido R, Bravo L, Saura-Calixto F (2000) Antioxidant activity of dietary polyphenols as determined by a modified ferric reducing/antioxidant power assay. J Agr Food Chem 48, 3396-402. 